\section{Dr. Rafael García Pavón}

Universidad Anáhuac México

@ rgarcia@anahuac.mx
(iD) $0000-0001-8328-5192$
- Recibido / Received 25 de marzo de 2018

- Aceptado / Acepted 20 de abril de 2018

- Páginas / Pages De la 109 a la 123

- ISSN: 1885-365X

\title{
Bilbo Bolsón o de cómo un hobbit nos enseñó las virtudes de la fe
}

Bilbo Baggins or the way a bobbit teached us the virtues of faith

El presente trabajo tiene como objetivo presentar en el relato de El hobbit de J.R.R. Tolkien cuáles son las virtudes que se requieren para ejercer la fe como el modo en que nuestras elecciones hagan emerger de la vida la verdad y un sentido último, pero que no se expresan de modo directo, sino como un flujo del tiempo. Esto quiere decir que Tolkien tanto en su idea del relato fantástico como en la configuración de la historia y del carácter de sus personajes, nos presenta la fe y la libertad como dos ámbitos que se requieren mutuamente para realizarse. Así en este texto primero se muestra una reflexión sobre el sentido del relato fantástico y la recuperación del tiempo, segundo en qué sentido la aventura de Bilbo Bolsón es la de la fe, y tercero como la historia se puede comprender como el crecimiento de las virtudes de la fe en tres pruebas que Bilbo debe enfrentar: Gollum, Smaug y el regreso.

PALABRAS CLAVE: libertad, fe, virtud, Tolkien, tiempo.

The present work aims to present in the story of The Hobbit of J.R.R. Tolkien what are the virtues required to exercise faith as the way in which our choices make the truth and an ultimate sense, to emerge from life, that are not expressed directly, but as a flow of time. This means that Tolkien, both in his idea of the fantastic story and in the configuration of the history and character of his characters, presents faith and freedom as two areas that are mutually required to be performed. Thus in this text, we first expose a reflection on the meaning of the fantastic story and the recovery of time, secondly in what sense the adventure of Bilbo Baggins is that of the faith, and third how the story can be understood as the growth of virtues for faith in three tests Bilbo has to confront: Gollum, Smaug and the wayback..

KEY WORDS: freedom, faith, virtue, Tolkien, time.

Motto: "¡No!-dijo Thorin-. Hay en ti muchas virtudes que tú mismo ignoras, hijo del bondadoso Oeste. Algo de coraje y algo de sabiduría, mezclados con mesura. Si muchos de nosotros dieran más valor a la comida, la alegría y las canciones que al oro atesorado, éste sería un mundo más feliz" (Tolkien, 1991, p. 295). 


\section{Relato fantástico y recuperación del tiempo perdido}

¿Qué sería de nuestra existencia si solo consistiera en un paso indiferente, como el paso de las hojas de la primavera al otoño? ¿Qué sería de nuestro conocimiento si solo considerara verdad aquello de lo cual puede tener una certeza científica? ¿Qué serían nuestras creencias, valores y virtudes si solo creyéramos lo que podemos ver y nombrar con los sentidos? La existencia sería un mero pasar, el conocimiento un método mecánico y la creencia una simple evidencia, es decir, la existencia aburrimiento, el conocimiento recopilación de datos y la creencia desesperación hasta que el tedio y la indiferencia se vuelvan los hábitos por los cuales una sombra oscura traspase todas las creaturas del bosque -como se relata en El señor de los anillos- convirtiendo su bondadosa naturaleza, en horrendas creaturas de la mentira, ¿cuál mentira? La de ser dueños y poseedores del tiempo y la eternidad.

Este escenario no es fantasioso, sino los hechos de la historia o del terror de la historia como decía el pensador rumano Emil M. Cioran, en el cual el mal triunfa, desde los relatos históricos en el antiguo testamento y las noticias de los últimos tiempos. ¿Existe acaso una puerta de luz, un vestigio de la esperanza que cure el pasado, que redima el futuro, un sendero dentro de este Bosque Negro? ¿De qué modo podemos vencer la mentira cuando ésta se ha hecho sistema y ha dado lugar a creaturas como el Dragón Smaug que de forma codiciosa retiene un tesoro que no es suyo en el aislamiento de la montaña más lejana de la geografía de la Tierra Media? ¿Existe un modo de recuperar ese tiempo perdido, de esa conciencia eterna que nos vincula con lazos sagrados durante el tiempo a la verdad? Porque como decía el filósofo danés del siglo XIX Søren Kierkegaard, si todo lo que ocurre fueran actos inconscientes y estériles, «si un eterno olvido siempre voraz hiciese presa en todo y no existiese un poder capaz de arrancarle el botín jcuán vacía y desconsoladora no sería la existencia! Pero no es este el caso, y Dios que creó al hombre y a la mujer, modeló también al héroe y al poeta». (Kierkegaard, 1998, p. 11). Nos dio a Tolkien y a Bilbo, a Tarkovski y el cine; es mediante el relato poético en sentido amplio como narración, como creación o subcreación artística que el mundo puede ser re-encantado (Fernández Biggs, 2003, p. 67), solo un Bilbo podía robarle el tesoro que nos pertenece a la mentira de Smaug y a las tentaciones del anillo de Gollum.

El poeta, nos dice Kierkegaard, es aquel que si bien no puede llevar a cabo las hazañas del héroe sí es el genio de la evocación, el gran enemigo del olvido, mediante el recurso de la fantasía o el mito. El poeta es como si fuera lo mejor del héroe, pero sin la actualidad del mismo, por eso puede poner en claro sus cualidades, su historia, su realidad. El poeta, como decían los románticos, puede con la fantasía hacer explícitos los sentidos de lo que existe en su devenir temporal. Es un modo de mirar lo que el mundo es, ha sido y sobre todo lo que puede ser, y por ello invita a quien lo escucha a creer que lo recreado es posible y elegirse a realizarse dentro de esa historia.

La fantasía suspende el nivel de los hechos, pero recrea en el nivel de lo posible, es decir, de lo que la realidad es en su consistencia y esencia eterna, aunque no haya sido realizada en un tiempo y espacio concretos, en su amplio horizonte de sentido que representa la 
eternidad. La creación fantástica, como decía Tolkien, es un derecho humano (Tolkien, 2002b, p. 176; Fernández Biggs, 2003, pp. 66-67) porque a semejanza de quien hemos sido creados recreamos los horizontes de sentido y de posibilidad de lo que existe, por ello la fantasía, en ese sentido, recrea la verdad en el tiempo, pero no siendo esclava de los hechos. Por ello la creación fantástica, y en este sentido la literatura, no es una copia o imitación de lo real identificado con los hechos, sino la repetición de los horizontes de sentido que comprenden a los hechos, y de esta forma son un trazo de su plenitud, de su verdad. La fantasía no es así simple "imaginación fantástica", como un sucedáneo de la mentira, en la cual se crean mundos alternos a los hechos pero sin las condiciones de su realización. Es un recrear su sentido que da ocasión a la condición de la libertad de cursar de nuevo el horizonte de realización y por tanto de aprender a creer de nuevo más allá de los hechos, más allá de un tiempo y espacio determinados, de ese modo el tiempo se puede recuperar.

Por eso para Tolkien el relato fantástico, dentro del contexto desesperanzador de la literatura de su tiempo, tiene una doble virtud: primero, liberarnos de las ataduras de los hechos, entendidos como cierre del espacio significativo, como fueron dados en un determinado tiempo y cuya atadura nos obsesiona con la certeza de que no pueden ser de otra manera; por tanto la fantasía nos abre al sentido de la responsabilidad de la libertad en la realización de la historia y segundo, la fantasía nos dice que somos a imagen y semejanza de un creador: recreadores del sentido del mundo.

La verdad no está en los hechos sino en el descubrimiento de qué los hizo posible, en la comprensión de la propia condición o situación humana en la que se dan las posibilidades de un sentido completo, los hechos son solo modos de darse en un tiempo y espacio específicos. En este sentido la verdad se encuentra más en el relato fantástico que en la crónica de los hechos, y por tanto el relato fantástico hace posible que como lectores o escuchas o espectadores podamos reduplicar en nuestro propio tiempo las condiciones eternas de realización y así dar mayor luz sobre la verdad, y vencer de alguna forma la mentira.

Mientras la verdad la reduzcamos a la forma de sus hechos no habrá forma de comprendernos en ella, y en ese sentido no hay verdad alguna. En cambio, con el relato fantástico esa verdad se hace disponible para nuestro tiempo y llega a habitarnos de algún modo, por lo que podemos comprendernos en la verdad que representa, recreando el mundo que nos ha sido dado.

Los hechos nos esclavizan a vivir reducidos a una condición del mundo, la fantasía nos conecta con la posibilidad de comprender que nuestra existencia tiene un sentido mucho más amplio que la del tiempo y el espacio. Este relato fantástico es el que hace posible que podamos mediante nuestras elecciones conectar el ámbito de nuestra finitud con el amplio horizonte de lo posible, o para decirlo de otro modo, el significado concreto de nuestra existencia con el sentido total de la historia. La historia, es así, no los hechos que han ocurrido en el tiempo, sino la relación entre ese horizonte eterno con la singularidad del devenir de la libertad en el presente de su relato, configurándose en una historia concreta, en un tipo de temporalidad.

En otras palabras, los relatos fantásticos buscan hacer que el tiempo de la historia que ha ocurrido en el ámbito de un tiempo mítico o fuera del tiempo propio pueda ser contemporáneo con nuestro propio tiempo y nos habite, no por los hechos, sino por el horizonte de comprensión y la verdad que representa. Este tipo de verdades son las que solo se comprenden en el modo 
en que ellas pueden devenir, es decir, en su modo de realizarse. En otras palabras, el relato fantástico pretende hacernos creer de nuevo en un contexto de incredulidad y este creer de nuevo es lo que conecta la realidad posible como prefiguración de la verdad en el relato y la historia concreta de cada individuo, dejando de ser una mera especulación o un tiempo vacío, convirtiéndose en una historia real, es decir, en temporalidad, por eso nos dice Kierkegaard que la fe es el órgano de la historia (Kierkegaard, 2007a, pp. 90-92), porque al creer en lo pasado éste se hace incierto en su forma de haber sido y se hace cierto su horizonte de posibilidades, abriéndose a un nuevo porvenir. En el acto de fe es donde el pasado es premisa del porvenir y el porvenir destino del pasado en el presente mismo en el que se cree; de nuevo no en cuanto un hecho en específico, sino en cuanto a un modo de comprenderse y posicionarse ante la existencia como una conversión interior.

Esto es para Tolkien la esencia de los relatos míticos e incluso del Evangelio, porque como decía Mircea Eliade, en todos ellos no se pretende solo recordar un hecho o un momento, sino estar en presencia con el sentido completo de la historia en su origen que le da sentido a nuestro presente y en las posibilidades futuras que le otorga, es decir, para ser contemporáneos con la verdad, porque la verdad en este sentido no puede ser reducida solo a las categorías de la objetividad del intelecto sino que debe ser comprendida en su modo de realizarse en un sujeto, en este caso, en el propio que lee el relato. La fantasía es así, un modo de comunicación o de plenificación de la verdad en la medida en que nos mete en una historia que podemos comprender y experimentar un porvenir en la propia actualidad, para ponernos en situación de creerlo. Como nos dice Braulio Fernández Biggs: «Se trataba de nombrar las cosas de nuevo, de volver a darles vida, pues habían muerto». (Fernández Biggs, 2003, p. 75). La fantasía es un modo de recobrar la visión original de la realidad y en ese sentido es un propedéutico de la fe (Tolkien, 2002b, p. 178).

Los relatos de Tolkien, en particular El hobbit, pretenden hacernos contemporáneos con un modo de ser de la verdad acerca de la situación humana que es la fe, la cual no puede ser comprendida del todo por los tratados de sus conceptos o de su fijación en tiempo o espacio, sino en re-cursar de nuevo el horizonte de sus posibilidades.

\section{Bilbo Bolsón y la aventura de la fe}

La historia de Bilbo Bolsón, en la fantasía del relato de El hobbit, nos narra precisamente este modo de ser de la condición humana, la cual se realiza solo en la aventura de ser historia, es decir en la unión activa por medio de la fe, como elección interna de querer creer que es posible lo que la fantasía le prefigura con el carácter finito de su propia situación. Este ser historia significa que lo narrado en El hobbit no se queda en el confort del carácter bolsón (baggins) de Bilbo, ni se queda en las meras posibilidades de su carácter aventurero Tuk (Took), que hereda de sus padres, sino que Bilbo es la relación de los dos cuando sin dejar de ser un Bolsón se adentra a la aventura del relato que se narra de diversas formas dentro de El hobbit, el cual va transformando al pequeño Bilbo, le va otorgando dignidad y respeto entre los enanos.

Bilbo va conociendo la verdad del mundo en sus extrañas creaturas, el sufrimiento, el esfuerzo, lo cual le va otorgando un sentido dentro de la aventura de los enanos por recuperar 
su tesoro. Pero lo más importante, a mí parecer, es su relación con Gollum y Smaug porque denota con mayor claridad cómo la fe de Bilbo se pone a prueba, su carácter y valores salen a relucir frente a estas creaturas que bien podrían ser él mismo. En el abismo del mal Bilbo se da cuenta del esplendor del bien, ante los cuales Bilbo experimenta la compasión, y nos damos cuenta de que su sentido se encuentra conectado con una historia mayor aún no revelada. Pero en estas pruebas además se nos muestra que lo debe hacer solo en la confianza de Gandalf, pero no puede depender de Gandalf, debe ser por él mismo. Por ello nos dice Peter Kreeft que «son los hobbits quienes mejor ejemplifican la virtud epistemológica de la fe debido a su humildad (...) los hobbits muestran esta virtud porque son relativamente inocentes e infantiles, y esta aparente debilidad, es su fortaleza». (Kreeft, 2005, pos. 1490).

El hobbit es la historia de la fe como el centro de las grandes aventuras y relatos, con sus virtudes y condiciones, pero sobre todo como una tarea que dura toda la vida, es más, que sin ella no hay historia como tal y genera un modo de vida, no por nada decía Peter Kreeft que los personajes de Tolkien son criptocristianos, están en clave de una ética y antropología cristianas, pero no de forma explícita, sino como modo de comprender lo que se requiere para su conversión.

¿Cómo llega la fe a Bilbo, cómo se representa en este mundo de la Tierra Media por el que nos llevará Tolkien desde la perspectiva del pequeño hobbit? Primero hay que decir cuáles son las condiciones de la naturaleza del hobbit, que en mucho se asemejan a las nuestras. Bilbo tiene una doble naturaleza, la de Bolsón y la de Tuk. Pero mientras siga siendo un Bolsón no existe historia, la historia se inicia cuando el lado Tuk se pone en relación con el Bolsón. Este lado Bolsón es aquél que gusta del confort, de la seguridad, de la comodidad, y sobre todo del tener invitados siempre que sean esperados. El lado Tuk es cuando es despertado su interés por la aventura, por conocer lo desconocido, por la emoción o la pasión por salir de la comarca. Esta dialéctica es, como dice Kierkegaard, la de la condición humana como la expresa en Temor y temblor: por un lado, somos seres apegados a la propia finitud y necesidad de nuestro existir, y por otro estamos abiertos a posibilidades no realizadas que se debaten en una infinidad de fantasías. Bilbo, como muchos de nosotros, quiere quedarse cómodamente en su comarca, desde la cual no existe nada más que la intimidad y comodidad del hogar, el mayor respeto es nunca ser impredecible y ser un calculado miembro de la sociedad (Tolkien, 1991, p. 12). Pero en esta perspectiva nuestra vida es muy miserable, está confinada a ese pequeño hoyo del hobbit, el cual de por sí no es algo malo, sino malo es que no adquiera su perspectiva real en el sentido de la narración completa.

En el lado Bolsón no debemos involucrarnos, o sentirnos llamados a algo, ni arriesgarnos, sino simplemente vivir de acuerdo a las condiciones que se han establecido en la comarca, pero el pequeño Bilbo sin saberlo está llamado a comprenderse de verdad en el sentido completo de la historia, es decir, el sentido completo de nuestra vida no se reduce al ámbito de nuestra comarca, sino a ese en el que de alguna forma seremos invitados, invocados, por el poeta que es profeta y que se expresa en las canciones del hobbit, al ser despertado el lado Tuk.

El lado Tuk, es el lado de la fantasía, el que añora vivir en el relato y que se despierta como diría Pascal por las razones del corazón y nos sitúa en el umbral de la vida de la fe. Lo que denota El hobbit es cómo estamos cada uno de nosotros en nuestra condición de bolsones llamados a lo Tuk, es decir, a creer que es posible un camino de aventura y de bondad, llamados a realizar la temporalidad como esa conexión en nuestra singularidad de la propia finitud con la historia eterna o más completa de la eternidad y de esa forma a que el mundo no nos sea indiferente. 
Por ello la fe no puede despertarse de forma exterior o en las condiciones ya dadas del mundo y de su confort, porque entonces quedaría confundida con el dominio que tenemos del mundo, cuando en realidad el camino de la fe es el que nos abre a ponernos en relación de modo singular con el sentido completo de la realidad, pero esta apertura debe ser movida desde el corazón de la interioridad del mismo individuo. Puesto que la fe es un camino de historia personal, es singular, es intransferible de individuo a individuo, y no se refiere a ninguna condición ya existente, es el camino de la sub-creación como diría Tolkien.

Por ello en El hobbit la fe se presenta primero en su carácter de acontecimiento inesperado, lo cual será la constante de las aventuras posteriores, todas serán inesperadas. Gandalf y los enanos llegan al hogar del hobbit como invitados inesperados. A Bilbo, como buen hobbit, le gustan las visitas siempre que sean esperadas, pero el que llegue Gandalf con 13 enanos, si bien debe ser un buen anfitrión, no sabe ni quiénes son ni por qué debe acogerlos en su pequeño agujero hobbit. Solo le han dicho que buscan a alguien con quien compartir una aventura y que necesitan un saqueador, a lo cual Bilbo se niega desde el inicio, principalmente porque desordenan su agenda hobbit.

La fe no puede ser algo predecible ni calculado porque entonces no se involucraría la elección del personaje y no se adentraría a una historia de descubrimiento, por eso parece que Gandalf, quien desde el principio confía en Bilbo (Tolkien, 1991, p. 29) y hace a los demás confiar en él más que el mismo Bilbo, representa la sabiduría del misterio del sentido último que encierra la aventura, si bien no puede saber el final, sí puede vislumbrar los elementos del relato y las cualidades del hobbit. En otras palabras, si pensamos en algunos otros relatos sobre actos de fe, vemos que el acontecimiento inicial siempre fue inesperado, algo que hace salir de sí al personaje y ponerlo en situación incómoda, en un estado de ánimo de angustia como diría Kierkegaard. Porque la fe llama a la libertad de Bilbo a adentrarse en el porvenir que se denota en la providencia de Gandalf, pero esto significa ser consciente de que tiene posibilidades y de que es libertad, es decir, que la tarea de su vida está en relación con un mundo desconocido, el cual lo invita y llama, pero a la vez quiere quedarse en su sentido bolsón.

Lo primero que produce la visita inesperada es la angustia necesaria que permita al pequeño hobbit no tener pretextos o condiciones para no estar abierto al sentido de la aventura que se le presenta frente a sí. Pero esto no es suficiente, la fe no solo aparece como angustia, sino que debe prefigurarse como historia en el corazón del pequeño hobbit. En el sentido Pascaliano, la fe es esa razón del corazón que la razón no conoce y que en primera instancia nos parece absurda, no porque no tenga sentido o sea irracional, sino porque no la tiene para el sentido de confort y seguridad del lado Bolsón, para la razón calculadora. Tan no lo tiene que Bilbo será después a su regreso tratado como un extraño en la propia Comarca, es un escándalo para sus comarqueños que se embarque en esta aventura y Gandalf será considerado como quien distorsiona el apreciado orden de los hobbits. Es como dice Peter Kreeft, las epistemologías clásicas, como el racionalismo o el empirismo ignoran un modo más antiguo de conocer qué es la intuición, a lo cual Pascal apela como razón del corazón «lo que no es una justificación por el sentimiento, la emoción, o el deseo sobre la razón, sino una expansión del significado de la razón más allá de calculadora a intuición» (Kreeft, 2005, pos. 1454).

Tolkien representa esta razón del corazón con la fantasía misma que se genera en el interior de Bilbo con las canciones, con sus diálogos con Gollum y Smaug, con sus sueños. Lo interesante de esta razón del corazón es que no solo prefigura un futuro, sino que descubre 
al hobbit para sí mismo y transforma su origen. La prefiguración aparece con esa mezcla de simpatía y temor a la vez, él mismo aparece ante sí haciendo cosas que nunca se hubiera imaginado, por ello cuando las relata de nuevo trata de hacerlas sin el contenido de miedo o peligro real que le implicaron y su origen se ve transformado, porque mientras está lejos de la comarca su nostalgia por ella va haciendo más claros los valores de un hogar como el agujero hobbit, es decir, deja de ser un modo de confort y se convierte en un sentido de pertenencia y al mismo tiempo de insuficiencia, pues veremos que Bilbo solo se siente pleno en Rivendell (Tolkien, 1991, p. 61) entre los Elfos, por ello dice el narrador que solo ahí se olvidaba de la comarca y en El señor de los anillos, su anhelo es irse de nuevo a la aventura para llegar a Rivendell.

Esto se muestra en lo que se produce en el interior de Bilbo cuando los enanos entonan la canción de su misión al principio de El hobbit, la cual contiene, como dice Corey Olsen (Olsen, 2012, pp. 23, 30), un sentido profético, porque está toda la historia ahí narrada, pero a la vez contiene algunos elementos oscuros de los propios enanos, como que su interés no es solo recuperar el tesoro que Smaug les quitó, sino vengarse de él. Pero en la inocencia de Bilbo, Tolkien nos dice que dentro de él se generó la fantasía del valor de todas las cosas, el deseo de salir, de ver las montañas, los pinos y las cascadas, explorar las cavernas y sustituir el bastón por una espada, pero cuando pensó en el dragón se estremeció.

\begin{abstract}
Mientras cantaban, el hobbit sintió dentro de él el amor de las cosas hermosas hechas a mano con ingenio y magia; un amor fiero y celoso, el deseo de los corazones de los enanos. Entonces algo de los Tuk renació en él: deseó salir y ver las montañas enormes, y oír los pinos y las cascadas, y explorar las cavernas, y llevar una espada en vez de un bastón. Miró por la ventana. Las estrellas asomaban fuera en el cielo oscuro, sobre los árboles. Pensó en las joyas de los enanos que brillaban en las cavernas tenebrosas. De repente, en el bosque de más allá de Delagua se alzó un fuego -quizá alguien encendía una hoguera-, y pensó en dragones devastadores que invadían la pacífica colina envolviendo todo en llamas. Se estremeció; y enseguida volvió a ser el sencillo señor bolsón. (Tolkien, 1991, p. 25).
\end{abstract}

La fantasía como resultado de la realidad de lo dicho en la canción se transformó dentro de Bilbo en una imagen de su propia invocación, de su vocación, si bien en este momento sin sus condiciones fácticas, pero sí en su verdad, es decir Bilbo se ve no ya como un simple bolsón sino en relación con el valor de todas las cosas en sentido heroico, cumpliendo una tarea que le revela su sentido último. Como diría Kierkegaard, le prefigura su teleología interior (Kierkegaard, 2007b, pp. 244-245). No solo lo hace conocerse, sino ponerlo en la situación de elegirse en eso que se ha prefigurado. $Y$ cada uno de esos momentos en que esto ocurra dentro del corazón hobbit, estará en una situación de tomar decisiones por sí mismo.

Esta teleología interior es el preludio de la fe, pues por un lado como dicen tanto Tolkien ${ }^{1}$ en sus cartas acerca del hobbit y como dice Kierkegaard, se despertó dentro de él su naturaleza para la que ha sido elegido existir en la historia, su personalidad, es decir, no cualquiera puede ser Bilbo, pero no por serlo ya lo es, debe elegirse en eso que ha sido elegido y la fantasía lo pone en perspectiva.

1/ Tolkien menciona en sus cartas que «Bilbo fue elegido» (Tolkien, 2002a, p. 424, n. 281). 
Son estas decisiones, que se dan por la fe en lo prefigurado en la inocencia, angustia y pasión fantástica del corazón, las que revelan la verdad o el sentido real del camino que Bilbo debe seguir, se hace singular y al mismo tiempo se une con una historia de eternidad. Por eso la fe es en un primer momento esta pasión y coraje de creer que lo fantaseado es verdad no para un momento o un instante, sino que es verdad para mí y que elegirse o no elegirse en ello es como la vida o la muerte, es decir, es una lucha por la dignidad. En este sentido es que nos dice Peter Kreeft (Kreeft, 2005, pos. 1460) que el modo de la fe de conocer en las intuiciones de la fantasía implica un tipo de virtud original, la inocencia y por ello la verdad se da como relaciones de confianza con otros: en un primer momento con Gandalf, después en su propia suerte, lo que significa la presencia del sendero que debemos cruzar para que la historia se realice.

Por ello vemos al pequeño hobbit, a la mañana siguiente que todos se han preparado para la aventura, salir corriendo con la pasión de quien cree que lo que ha visionado no es una simple utopía, sino lo que sin saber del todo por qué, llena su deseo, su mente, y le da una fuerza que está más allá de su comarca. Es como lo que Kierkegaard nos dice sobre la historia de Abraham en Temor y temblor: Abraham como Bilbo, creen en virtud de algo que es absurdo, no creen en el absurdo, sino en virtud de ello, porque es la forma creativa de abrir la razón a la razón del corazón que es fantasía en su primer momento, en un segundo momento es elección y veremos que en un tercer momento requiere una serie de virtudes. Los dos creen que lo que se espera se realizará en tiempo presente, no en un futuro abstracto, y los dos requirieron una pasión mayor que un deseo para embarcarse en ese viaje.

Este movimiento de fe se da en Bilbo como un doble movimiento que va de lo Bolsón a lo Tuk y de lo Tuk a lo Bolsón, y en el medio es que Bilbo se va denotando en su historia. Lo cual es análogo a lo que Kierkegaard menciona del movimiento de la fe en cualquier individuo mediante la metáfora de que existir es como un gran baile. Es decir, la existencia es un movimiento de síntesis entre las condiciones finitas, necesarias de la existencia, con las condiciones infinitas, posibles de la misma, lo cual se representa como tener un pie en la tierra, y el otro como tener un pie en el aire, en cierta forma el lado Bolsón de Bilbo y el lado Tuk. La fe es así un movimiento doble: primero la reflexión o la fantasía que me lleva de lo Bolsón a lo Tuk, es decir a imaginar otros mundos posibles, pero que no parten de la nada, sino de las mismas condiciones en las que nos encontramos, pero sin esclavizarse a ellas, ahí es donde aparece la angustia, pero movidas por el corazón. Y el segundo movimiento, que es la fe propiamente, de lo Tuk a lo Bolsón, es creer que es posible aquí y ahora lo que la fantasía nos dice de nosotros mismos, pero este creerlo es un acto de confianza, de pasión, pero al mismo tiempo de esperanza en que será así de cierta forma, una confianza que si bien se despierta en la pasión fantástica, requiere de otro para hacernos confiar, en el caso de Bilbo de Gandalf en principio, pero después la esperanza debe ser por sí mismo, como cuando entran al Bosque Negro o cuando se encuentra con Gollum, por lo que ahí vemos su verdadera fe (Kierkegaard, 1998, pp. 32-33).

Bilbo es de alguna manera un caballero de la fe, como dice Kierkegaard, porque no se resigna en ninguna de las aventuras - aunque siempre tiene la tentación a regresarse al confort de su agujero hobbit- la pasión inicial de su fe que lo ha movido a la aventura late dentro de sí no solo por el deseo de conocer, sino como vemos con Gollum, de amar la bondad de todas las creaturas. Lo que Bilbo va descubriendo, y que por ende nos va enseñando en su travesía, es el contenido de la verdadera fe, el creer que es posible la bondad en toda creatura a pesar de su perversión, y esta es la pasión de la fe, la cual Gollum 
perdió de alguna forma, y Smaug la aborrece. Bilbo como caballero de la fe, diría Kierkegaard, es quien habiendo dado el paso hacia la proyección infinita da el salto para su realización en lo finito, como dice Kierkegaard: «Se requiere pasión para esto. Todo movimiento del infinito se lleva a término por la pasión, y nunca una reflexión podrá producir un movimiento» (Kierkegaard, 1998, p. 34).

Lo que podemos aprender hasta este momento es que la fe es pasión por la verdad que se prefigura en la fantasía que proviene de la interioridad del propio corazón y que nos pone en situación de angustia o de elección, de confianza y esperanza, que lo proyectado sea un camino de verdad. La fe es ese acto por el cual entonces nos atrevemos a que lo Tuk irrumpa en lo Bolsón, para conectarnos con un sentido de trascendencia, el cual no se sabe de antemano, sino que se va desvelando en las situaciones en las cuales esa pasión original, esa fe, se pone a prueba. Además, la fe es un camino solitario no por estar aislado sino porque nadie, ni Gandalf, puede tomar esa decisión por nosotros. Por ello la fe está entre el confort y la aventura, lo predecible y lo impredecible lanzada por la confianza en ese porvenir con inocencia y humildad, haciéndonos disponibles a la propia transfiguración.

\section{Primera prueba de fe: Gollum}

Para que la fe sea real debe ser un creer en el tiempo presente y en este mundo, por eso la fe impulsa a Bilbo a salir de la comarca, lo cual indica que no es fácil, y no está exenta de peligros, esfuerzos y sufrimientos. En cada una de sus aventuras, y mientras más se van acercando a la montaña solitaria en donde reside Smaug, se encuentran con creaturas de diversa índole, desde salvajes como los wargos o las águilas, o creaturas malvadas con sed de maldad como los trasgos, o como la combinación de lo salvaje y lo humano en Beorn, y ante cada uno Bilbo tendrá que sortear por el bien de la misión, y no solo de él. Los peligros que implican vencer la tentación de ser un desertor, y por tanto un infiel, en cada uno de ellos el miedo lo posee, el anhelo de su hogar es su refugio, ante la falta de comida civilizada, por ejemplo.

La fe es un camino que implica sufrimiento porque el mundo como tal, inclusive la Tierra Media, no es perfecta ni se encuentra en la idealidad, sino que más bien la fe es el camino para descubrir realmente cómo es el mundo, pero a la vez vislumbrar dentro de él su camino de bondad. Esto es lo que realmente hace sufrir a Bilbo, y es la mayor tentación de todas, sobre todo cuando tiene la posibilidad de deshacerse de Gollum, ahí en ese momento, como dice Corey Olsen: Bilbo da un salto de fe (Olsen, 2012, p. 108).

¿Qué nos denota la relación de Bilbo con Gollum y Smaug en relación con su fe? Hay algunas semejanzas y diferencias entre las dos relaciones, pero en las dos situaciones Bilbo debe poner a prueba esa pasión inherente y al mismo tiempo la va a descubrir - de hecho podemos decir que es en todas las aventuras ${ }^{2}-$. Bilbo se va encontrando

2/ Si bien podría hacerse un análisis por cada aventura del hobbit, algo que ya ha realizado de algún modo Corey Olsen en su comentario sobre El hobbit me concentraré en tres momentos que podríamos decir que son icónicos del movimiento que lleva acabo Bilbo, que son: el encuentro con Gollum, con Smaug y al retorno a la Comarca, porque en los tres debe tomar una decisión que directamente afecta al tipo de hobbit en el que se convertirá, son decisiones de vida o muerte existencialmente hablando. 
con diferentes tipos de pruebas en las que tiene que poner en juego su coraje y su buen juicio para ayudar al cumplimiento de la misión, pero más por confianza en Gandalf y por la amistad y los deberes que ellas le han aportado con sus acciones, que por el tesoro mismo. En cada una de estas aventuras va ganando confianza en sí mismo, va ganando el respeto de los enanos hasta que en relación con Smaug está listo, como dice el narrador, para convertirse en un verdadero líder que hace los planes por sí mismo y por ello será otro tipo de hobbit.

Entre Gollum y Smaug se dan ciertas condiciones paradigmáticas que nos hablan con mayor fuerza de quién es Bilbo en esta aventura y cómo se denotan las virtudes de su fe. Las semejanzas entre Gollum y Smaug es que las dos son creaturas, por diversas razones, codiciosas, avariciosas y solitarias, en el sentido de encontrarse completamente aislados de todo lo que hace deseable y hermosa la vida. Pero Gollum ha caído en esta situación por el poder del anillo y su posesión, hasta quedar confinado al fondo de las montañas en donde reinan la oscuridad, el frío, el silencio desolador, las sombras, las formas de vida más ínfimas del mundo y donde se es difícil de encontrar (Tolkien, 2002a, p. 275, n. 181). En cambio Smaug tiene como su propia naturaleza la avaricia, la codicia, sin sentido alguno, sueños de violencia y de diversión sabiéndose el más grande y poderoso sobre la tierra. Gollum no es vanidoso, Smaug es la vanidad total.

Por eso cuando Bilbo se relaciona con Gollum tiene sentimientos encontrados, por un lado de desconfianza, de miedo, pero no de terror; y por otro lado de compasión. En cambio con Smaug, el miedo lo siente desde la punta de los dedos hasta la punta del último cabello, que por cierto perderá al escapar de la furia del dragón. Sin embargo, tanto Gollum como Smaug en sus sueños y sus deseos tienen que ver solo con ellos, aunque en Gollum hay recuerdos dolorosos de su vida original, tan dolorosos de no serlo ya que los odia. Las dos creaturas mienten, engañan, y sus acertijos pretenden no comprender la verdad, ni respetar las reglas del juego, sino hacer caer a Bilbo en la trampa y destruirlo con su poder. Gollum responde con desesperación cuando sabe que pierde el anillo y Smaug responde con ira al saber un pedazo de su tesoro robado, pero los dos codician algo que no les da nada a cambio, sino un ensimismamiento más en sí mismos que harán cualquier cosa por seguirlo poseyendo, porque por sí mismos no tienen otro valor.

Por ello la relación de Bilbo con Gollum y Smaug podríamos decir que son las pruebas fundamentales de su fe contra dos representaciones del mal ${ }^{3}$, de uno que ha caído en el mal por su relación y otro que el mal lo ha tomado como forma de ser. Finalmente el mal no es la creatura, sino la relación de su vida con lo que lo ha hecho degradarse y depravarse, pero a tal grado que su redención solo puede encontrarse en un tipo de muerte, en una eucatástrofe como la llama Tolkien (Tolkien, 2002a, p. 276, n. 181). Inclusive otras creaturas, más no Bilbo, como Thorin o los hombres, se ven influenciados por el mal de uno o de otro.

En el magistral capítulo de los acertijos con Gollum de El hobbit se develan los aspectos de lo que significa el carácter del bien y el carácter de quien ha perdido el bien, es decir la fe. Tanto por el contenido de los acertijos, como por las intenciones al realizarlos. En Gollum

3/ Tom Shippey de hecho cree que el tema fundamental de la literatura de Tolkien es: «el origen y naturaleza del mal» (Shippey, 2003, p. 11). 
vemos en cierta forma la degradación de lo Bolsón y lo Tuk del hobbit. Por un lado, nos dice el narrador, ha perdido a sus amigos, ha quedado aislado en la oscuridad despreciado por todos, Gollum se ha obsesionado con la posesión del anillo a tal grado que solo habla y se expresa como si se hablará a sí mismo. Sus propios recuerdos de su vida anterior le son dolorosos, por ya no poder ser ese y no poder abandonar el anillo, pero paradójicamente cuando se encuentra con Bilbo solo podía pensar en acertijos para relacionarse con él. En este aspecto los acertijos en Gollum revelan en su contenido aspectos de la oscuridad de su vida, aspectos de forma horrible y difíciles, en los que él se sentía con ventaja y en los cuales como dice Corey Olsen se revela su desprecio, egoísmo, encierro en sí mismo y pretensión de apoderarse de Bilbo (Olsen, 2012, pp. 104-107). En cambio, a Bilbo muchos de los acertijos que se le ocurren le vienen no por malicia sino de las cosas buenas y agradables del mundo, y sus respuestas son a veces por suerte (Tolkien, 1991, p. 78).

Y en este estado de cosas, sabemos que el último acertijo que le lanza Bilbo a Gollum "¿qué tengo en mi bolsillo?», algo que Bilbo pensó por suerte, Gollum no podría contestar de ninguna forma pues se había encontrado el anillo y no era algo usual. Esto hace al mismo tiempo que Gollum pierda y se enfurezca suponiendo que trae el anillo consigo. Vemos la malicia de Gollum cuando piensa de todas las formas posibles cómo matar a Bilbo, en ese momento es que Bilbo al usar la invisibilidad del anillo está en cierta ventaja con Gollum y siente la posibilidad de hacer lo mismo que él hubiera hecho, matarlo, en ese momento la pasión de su fe irrumpe como una razón del corazón, una extraña razón, que le hace perdonarle la vida:

Una súbita comprensión mezclada con horror asomó en el corazón de Bilbo: un destello de interminables días iguales, sin luz ni esperanza de algo mejor, dura piedra, frío, pescado, pasos furtivos, y susurros. Todos estos pensamientos se le cruzaron como un relámpago. Se estremeció. Y entonces, de pronto, en otro relámpago, como animado por una energía y una resolución nuevas, saltó hacia adelante... un salto a ciegas (Tolkien, 1991, p. 96).

Como dice Corey Olsen el resultado es «una nueva fuerza que lo propulsa literalmente a la luz que buscaba. Su decisión moral se convierte en un salto de fe, un salto en la oscuridad, y fuera de la oscuridad» (Olsen, 2012, p. 108). Un salto de fe que se acompaña de la suerte y el buen juicio y la fuerza de voluntad, como les dirá Gandalf al entrar al Bosque Negro. Por ello encontrarse el anillo es un modo de tener suerte, porque la suerte implica una causalidad que no es del mundo, una presencia de la contingencia y de lo inesperado, y una dirección al bien si sabemos leer su acontecer, pero la suerte va aparejada de la fe, por lo cual a partir de ahí el anillo será un medio para el bien.

Es en este momento cuando la fe en Bilbo lo empieza a transformar y con ella la historia (Tolkien, 2002a, p. 275, n. 181). Al ver las maldiciones y actos de Gollum en la escapada de Bilbo vemos sus diferencias más marcadas y el significado de la decisión moral del Hobbit, como nos dice Corey Olsen, Gollum se queda sin nada más que con el odio eterno de aquel que le enseñó misericordia y Bilbo sigue corriendo hacia la esperanza del escape, a pesar del hecho de que su compasión por Gollum ahora trae su corazón a su boca (Olsen, 2012, pp. 109-110), ha dejado de ser una víctima pasiva y se ha convertido en alguien activo dentro 
de la aventura. Esta actividad poco a poco lo prepara para enfrentarse al dragón Smaug, no por casualidad sino por su propia voluntad.

Eso nos deja ver que la fe de Bilbo no está como en los enanos probablemente movida por una meta o un objeto en particular, sino por descubrir el mundo como lo que realmente es, no por nada le encantaban los mapas, esa fe que descubre la bondad en toda creatura, y se vuelve la mayor pasión del hombre ${ }^{4}$, que requiere coraje, fantasía, sufrimiento, solo descansa cuando está entre los elfos. Por ello cuando entre enanos y hombres se pelean por repartirse el tesoro una vez muerto el dragón Smaug, Bilbo se atreve a tomar la decisión de llevarle la piedra tan ansiada por Thorin a los hombres para tratar de conciliar la paz entre ellos. Inclusive al final después de toda batalla, la fe de Bilbo se vuelve la pasión ardiente de regresar al hogar.

\section{Segunda prueba de fe: el dragón Smaug}

En su relación con Smaug, Bilbo ya ha pasado por varias aventuras en las que poco a poco no solo se ha ganado el respeto de los enanos, sino que se conoce mejor en sus habilidades y sabe cómo y cuándo usar el anillo, ha adquirido cierta sabiduría.

El dragón Smaug es mucho más poderoso, no se lo encuentra por casualidad como con Gollum, sino que va al encuentro con él. Todo a su alrededor lo ha destruido el poderoso Smaug y reposa sobre el tesoro con todo su cuerpo. Además Smaug (Tolkien, 1991, pp. 221-223) no tiene recuerdos de otra vida diferente, sino de batallas heroicas, se regocija en la violencia, venganza, ira y terror, es decir de la soberbia que satisface su vanidad: el poder.

Aquí Bilbo ya no es el miembro pasivo de la aventura, sino que: «se había convertido en el verdadero líder de la aventura. Empezaba a tener ideas y planes propios» (Tolkien, 1991, p. 227). En este escenario Bilbo pasa dos pruebas de su fe, la primera la paciencia con la que deben esperar para poder comprender cómo entrar al aposento del dragón. Y debe decidir o no entrar, con Gollum la decisión era cómo escapar y al final matarlo o no para lograrlo. Cuando se le ocurre cómo entrar, pasa la primera prueba, confiar en sí mismo, como dice en el capítulo 12 de El hobbit, empezó a confiar más en su buena suerte que en los viejos tiempos, es decir, su confianza se da más en el devenir mismo de la historia que en el confort de su seguridad. Al entrar, la segunda prueba de fe que debe pasar Bilbo es no ser seducido por lo grandioso del tesoro y del dragón Smaug, así como el poder seductor de su palabra que puede hacerlo dudar de la bondad de sus amigos y de su propia aventura, hacerlo dudar de su corazón, de su fe.

El enfrentamiento entre Bilbo y Smaug, es entre lo más grande, poderoso y perverso y lo más pequeño, insignificante e ingenuo. Los acertijos y la palabra de Smaug son más maliciosos que los de Gollum porque no pretenden solo engañar al hobbit, sino hacerlo dudar de su propia fe, robarle su pasión y sustituirla por el miedo, la avaricia y la codicia, como nos dice en El hobbit:

Y Smaug rio con fuerza. Tenía un corazón astuto y malvado, y sabía que estas conjeturas no estaban mal encaminadas [...] Apenas me creeréis, pero el pobre Bilbo estaba de veras muy desconcertado [...] una fea sospecha le apareció ahora en la

4/ Como dice Kierkegaard: «La fe es la más alta pasión del hombre» (Kierkegaard, 1998, pp. 104-105). 
mente ¿habían olvidado los enanos también este punto importante, o habían estado riéndose de él con disimulo todo el tiempo? La charla de un dragón causa este efecto en la gente de poca experiencia. Bilbo, no tenía que haber bajado la guardia; pero la personalidad de Smaug era en verdad irresistible (Tolkien, 1991, pp. 231-232).

La resistencia que Bilbo pone a ello es aferrarse al sentido de la historia en la que se encuentra, lo cual se denota porque los nombres que se da a sí mismo frente a la pregunta del dragón de «¿quién eres tú?», son los logros de sus batallas, por las cuales ha sido respetado por los enanos y le dan el sentido de estar ahora frente al gran Smaug. En otras palabras, los nombres que dan sentido a su fe. En este sentido Bilbo supera la seducción del dragón, pues este no suponía la bondad intrínseca del hobbit, no es como los enanos. Y por ello Bilbo se da cuenta de que para saber su punto débil solo lo logrará aludiendo a su vanidad. Podríamos ver en su forma de enfrentarse al dragón el modo como debe enfrentarse el bien contra el mal, no lo puede hacer en sus propios términos, es decir en enfrentar ego contra ego, poder contra poder, sino precisamente haciendo invisible, no diciéndole su nombre, aludiendo a su vanidad, es el propio mal el que se pone en condición de deshacerse a sí mismo, el poder del hobbit contra Smaug no es su fuerza, sino precisamente una astucia que sabe que no puede confrontarlo directamente, no está en su manos deshacer el mal, pero si ponerlo en condición de que se enfrente consigo mismo.

Bilbo escapa con vida, pero sin pelo, y afronta la tercera prueba de su fe, cuando se han dado cuenta de que el dragón ha muerto, y ésta es ¿cuál es el sentido de recuperar finalmente el tesoro? ¿cuál es el verdadero tesoro?

\section{La prueba de fe final de Bilbo: el regreso}

Así como con Gollum Bilbo ejerció la piedad como acto de fe, con Smaug ejerció prudencia y valentía como acto de fe pero, sobre todo, en ambos no perdió la inocencia original de las razones del corazón que dieron lugar a su aventura. En estas partes de El hobbit, Bilbo constantemente se enfrenta con la prueba más dura, ¿cuál es el sentido último de su fe? Esto es, de la aventura misma, pues el dragón ha muerto, ya han recuperado el tesoro, lo que amenaza a la fe en este momento es la falta de sentido de los esfuerzos de la misma, y que Bilbo descubrirá en el sentido de la amistad, la solidaridad y el compartir la bondad de todas las cosas que crecen. Esto es lo que vemos en su intento de conciliar a hombres con enanos, en sus memorias que nos va relatando mientras lleva a cabo el camino de regreso con Gandalf a la Comarca, pues en ellas todas las cosas bellas y buenas en los diferentes sitios de sus aventuras con creaturas monstruosas, son traídas al presente como las enseñanzas de su aventura.

La fe es una tarea que dura toda la vida, es una prueba constante de lo que somos, es lo que movió a la aventura y Bilbo nos enseña que lo más importante es el regreso a casa con lo aprendido como virtud y no con el tesoro en las manos. Por eso deben luchar contra la avaricia de los hombres y los enanos, batalla que se libra en realidad contra el mal y se dispersan las envidias, con los trasgos y wargos. De nuevo vemos la fe de Bilbo en relación con la posibilidad de un encuentro de solidaridad entre ellos, la guerra de los trasgos fue en cierta medida una buena eucatástrofe, así Thorin se reconcilia al fin con la historia de sus padres. 
Como dice al final la fe no quiere posesiones, la fe descubre el amor, se gana la amistad, se pierde el oro, la fe es la mayor pasión del hombre que surge del corazón de las profecías que llaman a la realización de una vocación interior o teleología interior que requiere coraje, valentía, prudencia, sabiduría, buen juicio, astucia, pero sobre todo fuerza de confianza para no caer en los artilugios del mal y saber amar hasta a los más desdichados del cuento. Relación por la cual la temporalidad adquiere un sentido en conexión con una historia más grande; no son los hechos, no son los objetos o las metas, sino el amor que comprende la belleza del mundo en el que nos encontramos y nos dispone a luchar, a no dudar, a conservar la inocencia como una virtud, por lo cual se regresa a casa como un extraño (Tolkien, 1991, pp. 306-308), como el que perdió su reputación, de tal forma que Bilbo se vuelve el nuevo narrador, porque de la aventura a su comprensión en la narración algo se quedó en el olvido, y por ello incita a repetir la aventura, a que cada generación, como dice Kierkegaard y como heredará Frodo, ponga a prueba de nuevo esta fe.

Al final la prueba de fe es creer en que el sentido de lo prometido se cumplirá, estas profecías son las razones del corazón que aparecen en cada uno como la invitación a participar de la historia, como le dice Gandalf a Bilbo al final de la historia:

¡entonces las canciones de las viejas profecías se han cumplido! ¡De alguna manera! -dijo Bilbo-. ¡Claro! -dijo Gandalf-y ¿por qué no tendrían que cumplirse? ¿No dejarás de creer en las profecías solo porque ayudaste a que se cumplieran? No supondrás ¿verdad? que todas tus aventuras y escapadas fueron producto de la mera suerte, para tu beneficio exclusivo. Te considero una gran persona, señor Bolsón y te aprecio mucho; pero en última instancia jeres solo un simple individuo en un mundo enorme! (Tolkien, 1991, p. 310).

Por ello el acto final de fe de Bilbo es una expresión de agradecimiento de que el sentido de todo ello no es la soledad, sino un ámbito de una comunidad trascendente, y por ello termina diciendo: «iGracias al cielo! -dijo Bilbo riendo, y le pasó el pote de tabaco».

\section{Bibliografía}

FERNÁNDEZ BIGSS, Braulio (2003). Tolkien y el reencantamiento del mundo. Santiago de Chile: Ediciones Universidad Católica de Chile.

KIERKEGAARD, Søren (1998). Temor y temblor. Madrid: Técnos.

KIERKEGAARD, Søren (2007a). Migajas filosóficas o un poco de filosofía. Madrid: Trotta.

KIERKEGAARD, Søren (2007b). "El equilibrio entre lo estético y lo ético en la formación de la personalidad".

En: KIERKEGAARD, Søren. O lo uno o lo otro. Un fragmento de vida II. Madrid: Trotta.

KREEFT, Peter J. (2005). The Philosophy of Tolkien. The worldview behind The lord of the rings. San Francisco: Ignatius Press. (Kindle iPhone 6s).

OLSEN, Corey (2012). Exploring J.R.R. Tolkien's The hobbit. New York: Houghton Mifflin Harcourt

Publishing Company.

SHIPPEY, Tom (2003). J.R.R. Tolkien. Autor del siglo. Barcelona: Minotauro.

TOLKIEN, J.R.R. (1991). El hobbit. Barcelona: Minotauro.

TOLKIEN, J.R.R. (2002a). Cartas. Barcelona: Minotauro.

TOLKIEN, J.R.R. (2002b). Sobre los cuentos de hadas. Barcelona: Minotauro. 